\title{
Tumor cell PD-LI predicts poor local control for rectal cancer patients following neoadjuvant radiotherapy
}

This article was published in the following Dove Press journal:

Cancer Management and Research

29 June 2017

Number of times this article has been viewed

\author{
Lingdong Shao* \\ Qingqin Peng* \\ Kaixin $\mathrm{Du}^{*}$ \\ Junyan $\mathrm{He}$ \\ Yaping Dong \\ Xiaoyi Lin \\ Jinluan Li \\ Junxin $\mathrm{Wu}$
}

Department of Radiation Oncology, Fujian Medical University Cancer Hospital, Fujian Cancer Hospital,

Fuzhou, People's Republic of China

*These authors contributed equally to this work
Correspondence: Junxin Wu Department of Radiation Oncology, Fujian Medical University Cancer Hospital, Fujian Cancer Hospital, 420 Fuma Road, Jinan District, Fuzhou 3500 I4, People's Republic of China Email junxinwu@।26.com

\begin{abstract}
The tumor cell (TC) PD-L1 expression has been reported by several studies in various types of cancer, and it reduces the cytotoxicity of T-cells toward cancer and evades the anticancer immune response. Herein, our study focuses on the impact of PD-L1 expression in prognosis and the correlation with clinical prognostic factors for local advanced rectal cancer with neoadjuvant radiotherapy (RT). A total of 68 rectal cancer patients treated with neoadjuvant RT were retrospectively enrolled in the present study. PD-L1 expression was investigated using immunohistochemistry. A regression model was used to identify prognostic factors associated with the disease-free survival, the local recurrence-free survival (LRFS), and the overall survival rates. The median follow-up was 32.5 months. Seven patients presented TC PD-L1 positive (TC PD-L1+), while the others were TC PD-L1 negative (TC PD-L1-). TC PD-L1+ patients showed frequent tumor recurrence than TC PD-L1- patients. Several patients with TC PD-L1- underwent long-course RT. TC PD-L1 expression was similar to interstitial cell (IC) PD-L1 expression, and the relationship between IC PD-L1 and pathological T stage was observed. TC PD-L1+ was related to poor LRFS. The multivariate analysis showed TC PD-L1+ as an independent negative prognostic factor for LRFS. In conclusion, TC PD-L1 expression putatively predicts the LRFS for patients with rectal cancer following neoadjuvant RT. The patients with TC PD-L1+ are susceptible to high local recurrent rate, thereby proposing a novel immunotherapeutic strategy for PD-L1 inhibition-mediated control.
\end{abstract}

Keywords: PD-L1, rectal cancer, neoadjuvant radiotherapy, prognosis

\section{Introduction}

Rectal cancer is the third most common form of cancer worldwide, with an estimated 134,490 new cases diagnosed in 2016 in the USA and 49,190 cases succumbing to mortality. ${ }^{1}$ For the local advanced rectal cancer (LARC) patients, current treatment strategies include preoperative radiotherapy (RT) or chemoradiotherapy, surgery, and chemotherapy. ${ }^{2}$ In addition, immunotherapy has been regarded as a promising therapeutic approach in anticancer treatment and has been investigated for several years. Although some studies had shown that rectal cancer patients are sensitive to immunotherapy, only small benefits in clinical practices have been achieved. ${ }^{3}$ The current success achieved through the inhibition of immune checkpoint pathways, such as programmed death 1 (PD-1) pathway, is a breakthrough in immunotherapy.

PD-1 is an inhibitory molecule that suppresses the proliferation of T-cells and the effector functions of activated T-cells through interaction with its ligand, the programmed death-ligand 1 (PD-L1). ${ }^{4}$ PD-L1 exhibits a broad tissue distribution and can provide inhibitory signals to PD-1+ immune cells for suppressing the immune 
responses. ${ }^{5}$ A majority of the tumor cells (TCs) can upregulate the expression of PD-L1, and thus, this mechanism may be advantageous to reduce the cytotoxicity of T-cells toward cancer and evade the anticancer immune response., ${ }^{6,7}$

Importantly, previous studies have shown that the TC PD-L1 expression is related to the response of anti-PD-1/ PD-L1 therapies. ${ }^{8}$ In clinical application, the blockade of PD-1 has led to antitumor activity and is certified by the US Food and Drug Administration (FDA) to treat melanoma and non-small-cell lung cancer patients. ${ }^{9}$ Interestingly, RT was shown to upregulate TC PD-L1 expression through modulating the radiation-induced biological effects. ${ }^{10}$ In addition, a series of preclinical studies has shown that the synergism of anti-PD-L1/PD-1 therapy and radiation could achieve better outcomes as compared to radiation alone in mice. ${ }^{11,12}$

In the case of rectal cancer, the study regarding the effect of PD-L1 expression (negative vs. positive) in patients with neoadjuvant RT is yet limited. Hence, the purpose of the present study was to investigate the impact of PD-L1 expression on the outcomes of patients with rectal cancer following neoadjuvant RT.

\section{Patients and methods}

\section{Patients}

We retrospectively examined formalin-fixed and paraffinembedded tumor tissue specimens of 80 patients who underwent preoperative RT at Fujian Provincial Cancer Hospital, Fuzhou, China, from June 2006 to February 2015. We conducted the research after the ethical approval of our institution. Of these, five patients were excluded from participation due to an exhibition of complete pathological response. Specimens from five cases were in poor condition, and two were not available. Finally, 68 patients were analyzed in this study. All tumor samples were diagnosed as rectal adenocarcinoma by pathologists. Patients who did not display distant metastasis at diagnosis and patients with more than one malignancy were excluded from the analysis. The study was approved by the ethics committee of Fujian Cancer Hospital, Fuzhou, China (No. YKT2016-025-01). As a retrospective study which involved review of patient medical records and tumor specimens, individual consent was not required by our ethics committee which approved the study as no individual patient identifiable information was utilized.

\section{Treatment}

The RT regimen consisted of short-course radiotherapy (SCRT) and long-course radiotherapy (LCRT), which was delivered using a conventional two-dimensional technique or intensity-modulated radiation therapy (IMRT). The SCRT was delivered in a dosage of $25 \mathrm{~Gy}$ in five fractions, while the LCRT consisted of a dose of 50.4 Gy in 28 fractions with a boost to the $2 \mathrm{~cm}$ margin of gross disease after delivering 45 Gy. In the two-dimensional conventional RT, the wholepelvic radiation-treated field encompassed the primary tumor and the nodes at risk, which was the region prior to the periphery of the sacrum and inferior to symphysis pubis, respectively. The clinical target volume in IMRT included the primary tumor and anorectal, mesorectal, pre-sacral, and internal iliac lymph nodes. 5-Fluorouracil (5-FU)-based chemotherapy was performed routinely. All patients received total mesorectal excision (TME), including low anterior resection (LAR) and abdominoperineal resection (APR). Surgery was conducted 1 week after the SCRT and 6-8 weeks after the LCRT was delivered.

\section{Immunohistochemistry (IHC)}

IHC was performed on 4- $\mu$ m-thick tumor specimen sections in paraffin-embedded blocks. The slides were deparaffinized using xylene and rehydrated using an alcohol gradient. Subsequently, the sections were washed in PBS $/ 0.05 \%$ Tween followed by endogenous peroxidase ablation using $3 \%$ peroxide-methanol to block the paraffin sections at room temperature. Followed by cooling at room temperature for $20 \mathrm{~min}$, the tissue sections were boiled in EDTA buffer, $\mathrm{pH}$ 8.0 , for $10 \mathrm{~min}$ for antigen retrieval. The nonspecific binding of antibodies would then be blocked. The slides were probed with rabbit anti-human PD-L1/CD274 monoclonal antibody (Clone SP142) (M4420, $0.1 \mathrm{~mL}, 1: 100$; Spring Bioscience, Pleasanton, CA, USA) at $4^{\circ} \mathrm{C}$ overnight or $37^{\circ} \mathrm{C}$ for $1 \mathrm{~h}$. The primary antibody was incubated on the slides for $10 \mathrm{~min}$ at room temperature. After rinsing the slides twice for $5 \mathrm{~min}$ per wash with $\mathrm{PBS} / 0.05 \%$ Tween, 3,3 $\varnothing$-diaminobenzidine was used for staining at room temperature without light for $10 \mathrm{~min}$ followed by counterstaining with hematoxylin. Two experienced investigators including one general pathologist, who were blinded to any clinical information, independently evaluated the expression of PD-L1. All reactions were conducted using positive and negative controls.

\section{Follow-up}

The patients' data were retrospectively analyzed. All patients were assessed clinically every 3 months for 2 years, every 6 months for 5 years, and annually after that. The tumor progression was diagnosed as local recurrence and distant metastasis either pathologically or radiologically. The local recurrence was defined as relapse in regions adjacent to the tumor bed or at the area of the anastomosis. 


\section{Statistical analysis}

The end point of this analysis included disease-free survival (DFS), local recurrence-free survival (LRFS), and overall survival (OS) rates. The time to event was estimated from the date of rectal surgery to the date of the event. The event for the DFS was defined as disease progression, relapse, or death; the LRFS was considered as relapse or death, and the OS was defined as death from any cause. The clinicopathological factors were compared between the groups using $\chi^{2}$ or the Fisher's exact test. The Kaplan-Meier method and log-rank tests were conducted for survival curve analysis and statistical differences. The prognostic relevance of variables was examined by the Cox regression model. $P$-value $<0.05$ in all the statistical tests was regarded as significant. The statistical analyses were conducted using the SPSS version 22.0 (IBM Corporation, Armonk, NY, USA).

\section{Results}

\section{Patient characteristics}

A total of 68 patients who were treated with neoadjuvant RT were eligible for analysis in this study. The patient's characteristics are summarized in Table 1. The median follow-up time was 32.5 months (range, 2-152 months). The cohort comprised of 46 (67.6\%) males and 22 (32.4\%) female patients. The median age of the patients analyzed was 53.5 years (range, 22-87 years). Patients with clinical TNM stages II and III were $27(39.7 \%)$ and 41 (60.3\%), respectively. Of all the patients, those with clinical T-stages 2 and $3(\mathrm{cT} 2 / 3)$ were $36(52.9 \%)$, and the rest had a cT4 stage. Those with the pathological $\mathrm{T}$ stage after neoadjuvant treatment (ypT) 2, 3, and 4 were 13 (19.1\%), 39 (57.4\%), and 16 (23.5\%), respectively. In all, $42(61.8 \%)$ patients presented clinical lymph node-positive disease (cN1/2), while the pathological $\mathrm{N}$ stage (pN) was pN1 in $24(35.3 \%)$ and $\mathrm{pN} 2$ in $15(22.11 \%)$ patients. In all, $17(25 \%)$ patients were identified as low grade and $51(75 \%)$ as an intermediate grade. With respect to the tumor location, 47 (69.1\%) patients had low rectal cancer (0-5 cm distant to verge), while 21 (30.9\%) patients had $>5-10 \mathrm{~cm}$ distance to verge. A total of $16(23.5 \%)$ patients had carcinoma nodules, 16 (23.5\%) patients had venous invasion, and 13 (19.1\%) patients had neural invasion. In all, 40 (58.8\%) patients received SCRT and the rest received LCRT. A total of 28 (41.2\%) patients received LAR and 20 (29.4\%) patients underwent preoperative chemotherapy (pre-CT).

\section{Expression of PD-LI in rectal cancer}

IHC staining detected PD-L1 localization both in the TCs and non-cancerous interstitial cells (ICs; Figure 1). PD-L1
Table I Patient characteristics

\begin{tabular}{|c|c|}
\hline Characteristics & Data, n (\%) \\
\hline \multicolumn{2}{|l|}{ Sex } \\
\hline Male & $46(67.6)$ \\
\hline Female & $22(32.4)$ \\
\hline \multicolumn{2}{|l|}{ Age (years) } \\
\hline Median (range) & $53.5(22-87)$ \\
\hline$\leq 50$ & $31(45.6)$ \\
\hline$>50$ & $37(54.4)$ \\
\hline \multicolumn{2}{|l|}{ Clinical TNM stage } \\
\hline II & 27 (39.7) \\
\hline III & $4 I(60.3)$ \\
\hline \multicolumn{2}{|l|}{ урТ stage } \\
\hline 2 & $13(19.1)$ \\
\hline 3 & $39(54.7)$ \\
\hline 4 & $16(23.5)$ \\
\hline \multicolumn{2}{|l|}{ ypN stage } \\
\hline 0 & $29(42.6)$ \\
\hline 1 & $24(35.3)$ \\
\hline 2 & $15(22.1)$ \\
\hline \multicolumn{2}{|c|}{ Pathological differentiation } \\
\hline Low grade & $17(25.0)$ \\
\hline Intermediate grade & $51(75.0)$ \\
\hline \multicolumn{2}{|l|}{ Carcinoma nodules } \\
\hline+ & $16(23.5)$ \\
\hline- & $52(76.5)$ \\
\hline \multicolumn{2}{|l|}{ Venous invasion } \\
\hline+ & $16(23.5)$ \\
\hline- & $52(76.5)$ \\
\hline \multicolumn{2}{|l|}{ Neural invasion } \\
\hline+ & $13(19.1)$ \\
\hline- & $55(80.9)$ \\
\hline \multicolumn{2}{|l|}{ Pre-RT } \\
\hline Long course & $28(4 \mid .2)$ \\
\hline Short course & $40(58.8)$ \\
\hline \multicolumn{2}{|l|}{ RT technology } \\
\hline IMRT & $14(20.6)$ \\
\hline Conventional RT & $54(79.4)$ \\
\hline \multicolumn{2}{|l|}{ Pre-CT } \\
\hline No & $48(70.6)$ \\
\hline Yes & $20(29.4)$ \\
\hline
\end{tabular}

Abbreviations: pre-RT, preoperative radiotherapy; RT, radiotherapy; IMRT, intensity-modulated radiation therapy; pre-CT, preoperative chemotherapy.

expression was shown in both the cytosol and cell membranes in rectal cancer samples. The level of PD-L1 expression was quantified on the basis of percentage of the stained area. PD-L1 expression in TCs was low for most patients, while that in ICs was relatively high (Figure 2). We defined TCs with $<1 \%$ of positive cells and $\geq 1 \%$ of positive cells as PD-L1 negative (PD-L1-; $\mathrm{n}=61,89.7 \%$ ) and positive (PD-L1+; $\mathrm{n}=7,10.3 \%$ ), respectively. With regard to PD-L1 expression in ICs, a cutoff of $10 \%$ was used to define "negative" $(n=51$, $75 \%)$ vs. "positive" ( $\mathrm{n}=17,25 \%)$ expression.

As shown in Table 2, we compared the outcomes and various clinicopathological factors between the groups. TC 

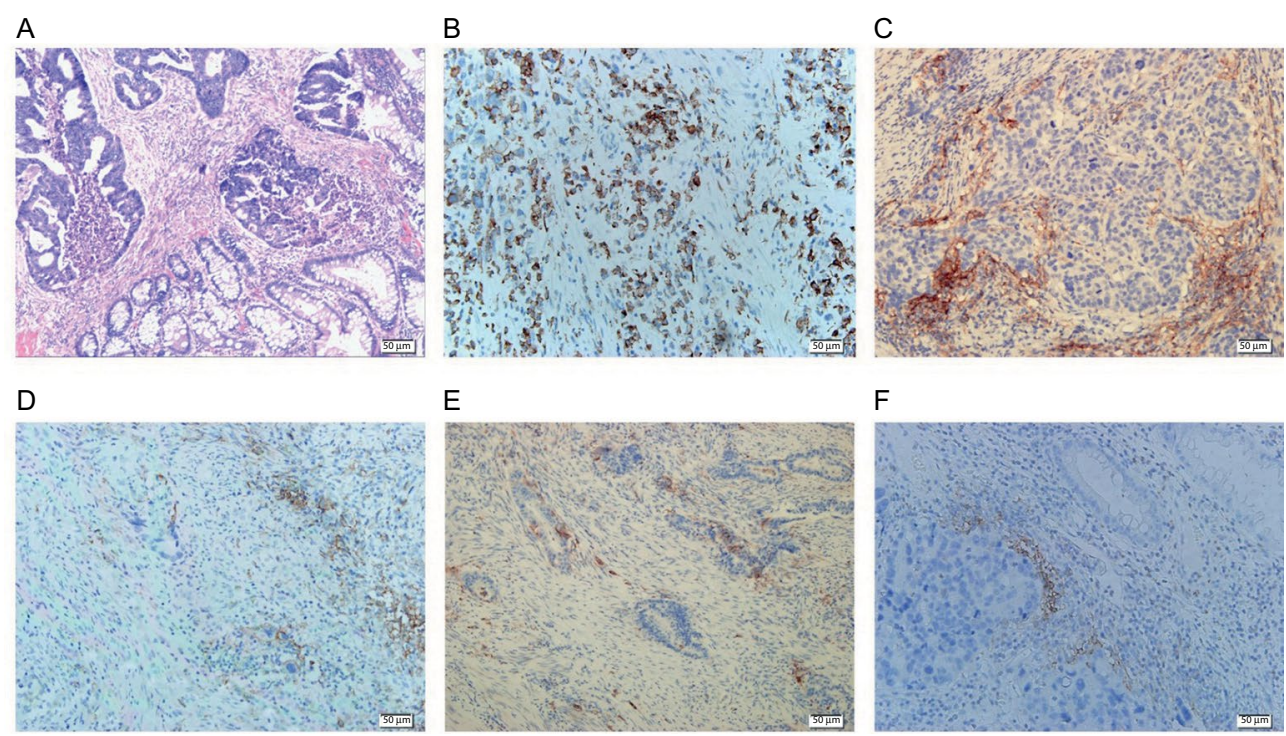

Figure I IHC staining of PD-LI expressions in rectal cancer (magnification 200x).

Notes: (A) The H\&E staining of rectal cancer after RT. (B) PD-LI expression in TCs. (C) PD-LI expression in ICs. (D) PD-LI expression both in TCs and ICs. (E) PD-LI expression in patients with SCRT. (F) PD-LI expression in patients with LCRT.

Abbreviations: IHC, immunohistochemistry; PD-LI, programmed death-ligand I; H\&E, hematoxylin and eosin; RT, radiotherapy; TC, tumor cell; IC, interstitial cell; SCRT, short-course radiotherapy; LCRT, long-course radiotherapy.

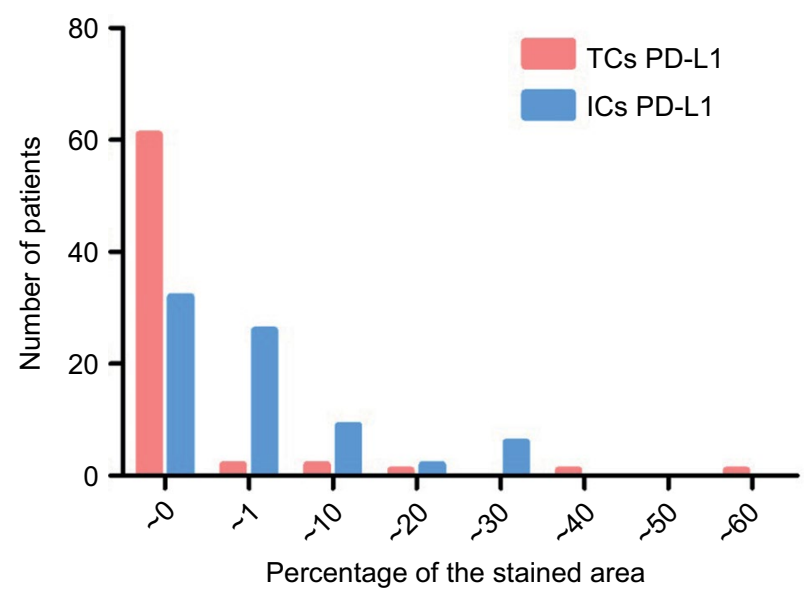

Figure 2 Distribution pattern of levels of PD-LI expression in TCs and ICs. Notes: The level of PD-LI expression was quantified on the basis of percentage of the stained area. PD-LI expression in TCs was low for most patients, while that in ICs was relatively high.

Abbreviations: PD-LI, programmed death-ligand I; TC, tumor cell; IC, interstitial cell.

PD-L1+ was significantly correlated to SCRT $(P=0.036)$, and recurrence $(P=0.044)$. No significant differences were observed except for pathological depth of invasion (pT; $P=0.039)$ in ICs. Additionally, PD-L1 protein expression in TCs was correlated to that in ICs $(P=0.009)$.

\section{Impact of PD-LI on the survival}

In order to assess the effect of PD-L1 expression in the TCs and ICs on patients' prognosis, we defined PD-L1 expression as positive expression and negative expression groups according to the immunostaining signal intensity. Herein, univariate analysis showed that factors affecting DFS were age, $\mathrm{pN}$ stage, carcinoma nodules, and TME method ( $P=0.028,0.023,0.013$, and 0.046 , respectively); $\mathrm{pN}$ stage, carcinoma nodules, and TC PD-L1+ expression were negative prognostic factors for $\operatorname{LRSS}(P=0.054,0.022$, and 0.010 , respectively). The factors affecting OS were a venous invasion and pathological differentiation $(P=0.055$ and 0.020 , respectively). The multivariate Cox regression model showed that the TC PD-L1+ expression (hazard ratio [HR] 6.001, 95\% $\mathrm{CI}=1.383-26.014, P=0.017$ ) was associated with LRFS. Furthermore, the pathological differentiation (HR 0.310, 95\% CI $=0.116-0.831, P=0.020$ ) was the independent prognostic factor (Tables 3-5). LRFS according to PD-L1 expression in TCs is shown by KaplanMeier curves in Figure 3. Patients with TC PD-L1+ had a significantly unfavorable prognosis in contrast to patients with TC PD-L1-.

\section{Discussion}

The present study focuses on the impact of PD-L1 expression in prognosis and the correlation with clinical prognostic factors for LARC with neoadjuvant RT. Here, we found that TC PD-L1+ was associated with tumor recurrence, and a correlation between IC PD-L1 and the ypT stage was also observed. Additionally, TC PD-L1- was correlated with significantly superior LRFS than PD-L1+ in these patients. Furthermore, to our knowledge, this is the first report regarding the different 
Table 2 Correlation between PD-LI expression and clinicopathological factors

\begin{tabular}{|c|c|c|c|c|c|c|}
\hline \multirow[t]{2}{*}{ Characteristics } & \multicolumn{2}{|c|}{ TC PD-LI } & \multirow[t]{2}{*}{$P$-value } & \multicolumn{2}{|l|}{ IC PD-LI } & \multirow[t]{2}{*}{$P$-value } \\
\hline & Positive & Negative & & Positive & Negative & \\
\hline \multicolumn{7}{|l|}{ Sex } \\
\hline Male/female & $4 / 3$ & $42 / 19$ & 0.406 & $12 / 5$ & $34 / 17$ & 1.000 \\
\hline \multicolumn{7}{|l|}{ Age (years) } \\
\hline$\leq 50 />50$ & $4 / 3$ & $27 / 34$ & 0.400 & $7 / 10$ & $24 / 27$ & 0.782 \\
\hline \multicolumn{7}{|l|}{ Clinical TNM stage } \\
\hline II/III & $3 / 4$ & $24 / 37$ & 1.000 & $6 / 11$ & $21 / 30$ & 0.779 \\
\hline \multicolumn{7}{|l|}{ cT stage } \\
\hline $2-3 / 4$ & $3 / 4$ & $33 / 28$ & 0.699 & $10 / 7$ & $26 / 25$ & 0.780 \\
\hline \multicolumn{7}{|l|}{ cN stage } \\
\hline $0 / 1-2$ & $3 / 4$ & $23 / 38$ & 1.000 & $6 / 11$ & $20 / 31$ & 1.000 \\
\hline \multicolumn{7}{|l|}{ урТ stage } \\
\hline $2 / 3 / 4$ & $1 / 4 / 2$ & $12 / 35 / 14$ & 1.000 & $7 / 7 / 3$ & $6 / 32 / 13$ & 0.039 \\
\hline \multicolumn{7}{|l|}{ ypN stage } \\
\hline $0 / 1 / 2$ & $2 / 3 / 2$ & $27 / 21 / 13$ & 0.675 & $9 / 6 / 2$ & $20 / 18 / 13$ & 0.485 \\
\hline \multicolumn{7}{|l|}{ Gross type } \\
\hline Ulcerative type/other & $7 / 0$ & $50 / 11$ & 0.588 & $14 / 3$ & $43 / 8$ & 1.000 \\
\hline \multicolumn{7}{|l|}{ Distance to verge $(\mathrm{cm})$} \\
\hline $0-5 />5-10$ & $6 / 1$ & $4 I / 20$ & 0.423 & $12 / 5$ & $35 / 16$ & 1.000 \\
\hline \multicolumn{7}{|l|}{ Pathological differentiation } \\
\hline Low grade/intermediate grade & $2 / 5$ & $15 / 46$ & 1.000 & $2 / 15$ & $15 / 36$ & 0.203 \\
\hline \multicolumn{7}{|l|}{ Carcinoma nodules } \\
\hline$+/-$ & $2 / 5$ & $14 / 47$ & 0.664 & $2 / 15$ & $14 / 37$ & 0.322 \\
\hline \multicolumn{7}{|l|}{ Venous invasion } \\
\hline$+1-$ & $3 / 4$ & $13 / 48$ & 0.342 & $4 / 13$ & $12 / 39$ & 1.000 \\
\hline \multicolumn{7}{|l|}{ Neural invasion } \\
\hline$+/-$ & $2 / 5$ & $11 / 50$ & 0.611 & $1 / 16$ & $12 / 39$ & 0.160 \\
\hline \multicolumn{7}{|l|}{ Pre-RT } \\
\hline Long course/short course & $0 / 7$ & $28 / 38$ & 0.036 & $5 / 12$ & $23 / 28$ & 0.394 \\
\hline \multicolumn{7}{|l|}{ RT technology } \\
\hline IMRT/conventional RT & $2 / 5$ & $12 / 49$ & 0.627 & $3 / 14$ & $1 \mathrm{I} / 40$ & 1.000 \\
\hline \multicolumn{7}{|l|}{ Pre-CT } \\
\hline No/yes & $7 / 0$ & $4 I / 20$ & 0.096 & $14 / 3$ & $34 / 17$ & 0.357 \\
\hline \multicolumn{7}{|l|}{ Surgical procedure } \\
\hline LAR/APR & $2 / 5$ & $26 / 35$ & 0.691 & $10 / 7$ & $18 / 33$ & 0.099 \\
\hline \multicolumn{7}{|l|}{ Metastasis } \\
\hline Yes/no & $2 / 5$ & $15 / 46$ & 1.000 & $5 / 12$ & $12 / 39$ & 0.748 \\
\hline \multicolumn{7}{|l|}{ Recurrence } \\
\hline Yes/no & $3 / 4$ & $6 / 55$ & 0.044 & $3 / 14$ & $6 / 45$ & 0.680 \\
\hline Progression & & & & & & \\
\hline Yes/no & $4 / 3$ & $18 / 43$ & 0.202 & $6 / 11$ & $16 / 36$ & 0.772 \\
\hline IC PD-LI & & & & & & \\
\hline$+1-$ & $5 / 2$ & $12 / 49$ & 0.009 & & & \\
\hline
\end{tabular}

Abbreviations: PD-LI, programmed death-ligand I; TC, tumor cell; IC, interstitial cell; pre-RT, preoperative radiotherapy; RT, radiotherapy; IMRT, intensity-modulated radiation therapy; pre-CT, preoperative chemotherapy; LAR, low anterior resection; APR, abdominoperineal resection; IC, interstitial cells.

PD-L1 expression between SCRT and LCRT in rectal cancer after neoadjuvant RT.

In accordance with the results mentioned earlier, PD-L1 protein expression and its correlation with disease outcome and prognostic value have been well demonstrated in various types of cancers, such as lung, ovarian, esophageal, and gastric, wherein TC PD-L1 was intensively associated with poor prognosis. ${ }^{13-16}$ In colorectal cancer, TC PD-L1 expression was significantly high in mismatch repair-deficient tumors when compared with mismatch repair-proficient tumors, and patients with a high PD-L1 expression had significantly poor outcomes in both. ${ }^{17,18}$ In our study, a correlation between TC PD-L1 - and improved LRFS was maintained in rectal cancer with neoadjuvant RT. Moreover, TC PD-L1showed a predisposition toward improved DFS and OS. Our results also coincide with a previous study in rectal cancer 
Table 3 Impact of PD-LI expression on the DFS of patients with rectal cancer

\begin{tabular}{|c|c|c|c|c|}
\hline \multirow[t]{3}{*}{ Variables } & \multicolumn{4}{|l|}{ DFS } \\
\hline & \multicolumn{2}{|l|}{ Univariate } & \multicolumn{2}{|l|}{ Multivariate } \\
\hline & HR (95\% CI) & $P$-value & HR (95\% Cl) & $P$-value \\
\hline \multicolumn{5}{|l|}{ Sex } \\
\hline Male & Reference & 0.264 & & \\
\hline Female & $1.672(0.679-4.118)$ & & & \\
\hline \multicolumn{5}{|l|}{ Age (years) } \\
\hline$\leq 50$ & Reference & 0.028 & Reference & 0.195 \\
\hline$>50$ & $0.334(0.133-0.893)$ & & $0.516(0.190-0.450)$ & \\
\hline \multicolumn{5}{|l|}{ cTNM stage } \\
\hline 2 & Reference & 0.948 & & \\
\hline 3 & $1.030(0.422-2.516)$ & & & \\
\hline \multicolumn{5}{|l|}{ урТ } \\
\hline 2 & Reference & 0.465 & & \\
\hline 3 & $2.160(0.479-9.754)$ & & & \\
\hline 4 & $2.712(0.558-13.174)$ & & & \\
\hline \multicolumn{5}{|l|}{ ypN } \\
\hline 0 & Reference & 0.023 & Reference & 0.470 \\
\hline 1 & $1.926(0.610-6.080)$ & & $1.336(0.402-4.442)$ & \\
\hline 2 & $4.459(1.489-13.356)$ & & $2.213(0.598-8.815)$ & \\
\hline \multicolumn{5}{|l|}{ Venous invasion } \\
\hline- & Reference & 0.163 & & \\
\hline+ & $1.944(0.764-4.948)$ & & & \\
\hline \multicolumn{5}{|l|}{ Neural invasion } \\
\hline- & Reference & 0.214 & & \\
\hline+ & $1.915(0.687-5.343)$ & & & \\
\hline \multicolumn{5}{|l|}{ Carcinoma nodules } \\
\hline- & Reference & 0.013 & Reference & 0.218 \\
\hline+ & $3.014(1.266-7.176)$ & & $1.963(0.689-5.558)$ & \\
\hline \multicolumn{5}{|c|}{ Pathological differentiation } \\
\hline Low grade & Reference & 0.489 & & \\
\hline Intermediate grade & $0.721(0.286-1.820)$ & & & \\
\hline \multicolumn{5}{|l|}{ Pre-RT } \\
\hline Long course & Reference & 0.821 & & \\
\hline Short course & $0.898(0.353-2.28 I)$ & & & \\
\hline \multicolumn{5}{|l|}{ Surgical procedure } \\
\hline LAR & Reference & 0.046 & Reference & 0.090 \\
\hline APR & $0.335(0.128-0.98 I)$ & & $0.409(0.145-1.150)$ & \\
\hline \multicolumn{5}{|l|}{ TC PD-LI } \\
\hline- & Reference & 0.061 & & \\
\hline+ & $2.880(0.952-8.719)$ & & & \\
\hline \multicolumn{5}{|l|}{ IC PD-LI } \\
\hline - & Reference & 0.560 & & \\
\hline+ & $1.326(0.5$ I $3-3.427)$ & & & \\
\hline
\end{tabular}

Abbreviations: PD-LI, programmed death-ligand I; DFS, disease-free survival; HR, hazard ratio; pre-RT, preoperative radiotherapy; LAR, low anterior resection; APR, abdominoperineal resection; TC, tumor cell; IC, interstitial cell.

patients after neoadjuvant chemoradiotherapy. ${ }^{19}$ However, as a result of heterogeneity, the predictive value of PD-L1 was questioned. ${ }^{20}$ One explanation of minimal predictive value might be that the tissue sample with PD-L1 negative might be distinct from other untested regions which were positive. Another explanation is the different cut point in different assays.
Furthermore, in our analysis, the high local recurrence rate was observed in those patients with TC PD-L1+. Several studies showed that tumor recurrence was related to the PD-L1 expression level. TC PD-L1 expression could inhibit the cytotoxic activity of CD8-positive T-cells and suppress production of T-cell interleukin-2 (IL-2), ${ }^{19}$ thereby further restraining T-cell proliferation and inducing T-cell 
Table 4 Impact of PD-LI expression on the LRFS of patients with rectal cancer

\begin{tabular}{|c|c|c|c|c|}
\hline \multirow[t]{3}{*}{ Variables } & \multicolumn{4}{|l|}{ LRFS } \\
\hline & \multicolumn{2}{|l|}{ Univariate } & \multicolumn{2}{|l|}{ Multivariate } \\
\hline & HR (95\% Cl) & $P$-value & HR (95\% Cl) & $P$-value \\
\hline \multicolumn{5}{|l|}{$\overline{\text { Sex }}$} \\
\hline Male & Reference & 0.074 & & \\
\hline Female & $3.336(0.888-12.715)$ & & & \\
\hline \multicolumn{5}{|l|}{ Age (years) } \\
\hline$\leq 50$ & Reference & 0.262 & & \\
\hline$>50$ & $0.449(0.1 \mathrm{II}-1.820)$ & & & \\
\hline \multicolumn{5}{|l|}{ cTNM stage } \\
\hline 2 & Reference & 0.666 & & \\
\hline 3 & I.343 (0.35I-5.340) & & & \\
\hline \multicolumn{5}{|l|}{ урТ } \\
\hline 2 & Reference & 0.999 & & \\
\hline 3 & $0.000(0.000-4.811)$ & & & \\
\hline 4 & $1.018(0.253-4.100)$ & & & \\
\hline \multicolumn{5}{|l|}{ ypN } \\
\hline 0 & Reference & 0.054 & Reference & 0.418 \\
\hline 1 & $1.334(0.188-9.491)$ & & $1.075(0.150-7.707)$ & \\
\hline 2 & $5.814(1.122-30.110)$ & & $3.245(0.459-22.936)$ & \\
\hline \multicolumn{5}{|l|}{ Venous invasion } \\
\hline- & Reference & 0.335 & & \\
\hline+ & $1.967(0.468-8.264)$ & & & \\
\hline \multicolumn{5}{|l|}{ Neural invasion } \\
\hline- & Reference & 0.118 & & \\
\hline+ & $3.142(0.746-13.227)$ & & & \\
\hline \multicolumn{5}{|l|}{ Carcinoma nodules } \\
\hline- & Reference & 0.022 & Reference & 0.344 \\
\hline+ & $4.673(1.248-17.494)$ & & $2.272(0.415-12.445)$ & \\
\hline \multicolumn{5}{|c|}{ Pathological differentiation } \\
\hline Low grade & Reference & 0.241 & & \\
\hline Intermediate grade & $0.446(0.116-1.717)$ & & & \\
\hline \multicolumn{5}{|l|}{ Pre-RT } \\
\hline Long course & Reference & 0.412 & & \\
\hline Short course & $0.512(0.103-2.538)$ & & & \\
\hline \multicolumn{5}{|l|}{ Surgical procedure } \\
\hline LAR & Reference & 0.204 & & \\
\hline APR & $2.806(0.57|-| 3.819)$ & & & \\
\hline \multicolumn{5}{|l|}{ TC PD-LI } \\
\hline- & Reference & 0.010 & Reference & 0.017 \\
\hline+ & $6.552(1.559-27.535)$ & & $6.001(1.383-26.014)$ & \\
\hline \multicolumn{5}{|l|}{ IC PD-LI } \\
\hline- & Reference & 0.426 & & \\
\hline+ & $1.760(0.438-7.705)$ & & & \\
\hline
\end{tabular}

Abbreviations: PD-LI, programmed death-ligand I; LRFS, local recurrence-free survival; HR, hazard ratio; pre-RT, preoperative radiotherapy; LAR, low anterior resection; APR, abdominoperineal resection; TC, tumor cell; IC, interstitial cell.

apoptosis. ${ }^{4,6}$ Hence, TCs escaped from immune cytotoxicity and therapeutic measures through the combination of PD-L1 and PD-1. ${ }^{9}$ This might be one of the reasons for tumor recurrence after treatment. Therefore, the ability of antitumor immunity by T-cells can be improved through the inhibition of PD-L1 expression.

TC PD-L1 expression was regulated by a series of signaling pathways and transcription factors. ${ }^{21}$ Our results showed that the TC PD-L1 was different in patients with LCRT and SCRT, suggesting that TC PD-L1 expression might be regulated by modifying the RT regimen. Radiation is deemed to induce local inflammatory or anti-inflammatory response on account of dose and fractionation. ${ }^{22,23}$ The PD-1/PD-L1 pathway has been well studied in the context of immune modulation and radiation. The PD-L1 expression was demonstrated as an upregulation after radiation treatment, which 
Table 5 Impact of PD-LI expression on the OS of patients with rectal cancer

\begin{tabular}{|c|c|c|c|c|}
\hline \multirow[t]{3}{*}{ Variables } & \multicolumn{4}{|l|}{ OS } \\
\hline & \multicolumn{2}{|l|}{ Univariate } & \multicolumn{2}{|l|}{ Multivariate } \\
\hline & HR (95\% Cl) & $P$-value & HR (95\% CI) & $P$-value \\
\hline \multicolumn{5}{|l|}{ Sex } \\
\hline Male & Reference & 0.424 & & \\
\hline Female & $0.598(0.170-2.109)$ & & & \\
\hline \multicolumn{5}{|l|}{ Age (years) } \\
\hline$\leq 50$ & Reference & 0.581 & & \\
\hline$>50$ & $0.767(0.300-1.965)$ & & & \\
\hline \multicolumn{5}{|l|}{ cTNM stage } \\
\hline 2 & Reference & 0.608 & & \\
\hline 3 & $1.300(0.477-0.537)$ & & & \\
\hline \multicolumn{5}{|l|}{ урт } \\
\hline 2 & Reference & 0.584 & & \\
\hline 3 & I.023 (0.272-3.842) & & & \\
\hline 4 & $0.525(0.103-2.679)$ & & & \\
\hline \multicolumn{5}{|l|}{ ypN } \\
\hline 0 & Reference & 0.204 & & \\
\hline 1 & $2.019(0.638-6.388)$ & & & \\
\hline 2 & $2.933(0.885-9.870)$ & & & \\
\hline \multicolumn{5}{|l|}{ Venous invasion } \\
\hline- & Reference & 0.055 & Reference & 0.037 \\
\hline+ & $2.909(0.976-8.668)$ & & $3.213(1.070-9.647)$ & \\
\hline \multicolumn{5}{|l|}{ Neural invasion } \\
\hline- & Reference & 0.962 & & \\
\hline+ & $\mathrm{I} .037(0.232-4.03 \mathrm{I})$ & & & \\
\hline \multicolumn{5}{|l|}{ Carcinoma nodules } \\
\hline- & Reference & 0.787 & & \\
\hline+ & $0.842(0.242-2.936)$ & & & \\
\hline \multicolumn{5}{|c|}{ Pathological differentiation } \\
\hline Low grade & Reference & 0.028 & Reference & 0.020 \\
\hline Intermediate grade & $0.335(0.126-0.891)$ & & $0.310(0.116-0.831)$ & \\
\hline \multicolumn{5}{|l|}{ Pre-RT } \\
\hline Long course & Reference & 0.284 & & \\
\hline Short course & $0.494(0.136-1.796)$ & & & \\
\hline \multicolumn{5}{|l|}{ Surgical procedure } \\
\hline LAR & Reference & 0.222 & & \\
\hline APR & I.19I (0.674-5.464) & & & \\
\hline \multicolumn{5}{|l|}{ TC PD-LI } \\
\hline- & Reference & 0.363 & & \\
\hline+ & $2.016(0.445-9.125)$ & & & \\
\hline \multicolumn{5}{|l|}{ IC PD-LI } \\
\hline- & Reference & 0.461 & & \\
\hline+ & $1.480(0.5$ I $8-4.233)$ & & & \\
\hline
\end{tabular}

Abbreviations: PD-LI, programmed death-ligand I; OS, overall survival; HR, hazard ratio; pre-RT, preoperative radiotherapy; LAR, low anterior resection; APR, abdominoperineal resection; TC, tumor cell; IC, interstitial cell.

led to radioresistance. ${ }^{10}$ On the other hand, preclinical studies present a combination of PD-1/PD-L1 pathway inhibition and ionizing radiation in mouse models, which achieved an excellent local tumor control through enhancement of anticancer immune responses. ${ }^{11,12}$ In the clinical study on AT-3 mammary tumors, ${ }^{10}$ blockade of the PD-L1/PD-1 pathway is effective on the primary tumor site, as well as in generating abscopal responses.
In addition to the TCs, the pertinence between IC PD-L1 and the ypT stage was also observed in this study. A previous study showed that, as the important element of ICs, immune cells' PD-L1 was correlated with early stage and high infiltration of T-cells. ${ }^{24}$ According to the pathologist, ICs contained a lot of lymphocytes in our study. Lymphocytes play a pivotal role in antitumor response, especially cytotoxic $\mathrm{T}$ lymphocytes. The favorable prognosis in colorectal 
A

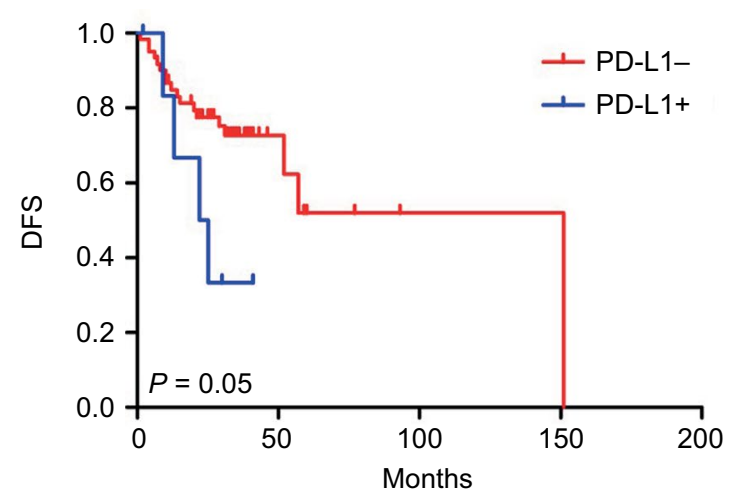

B

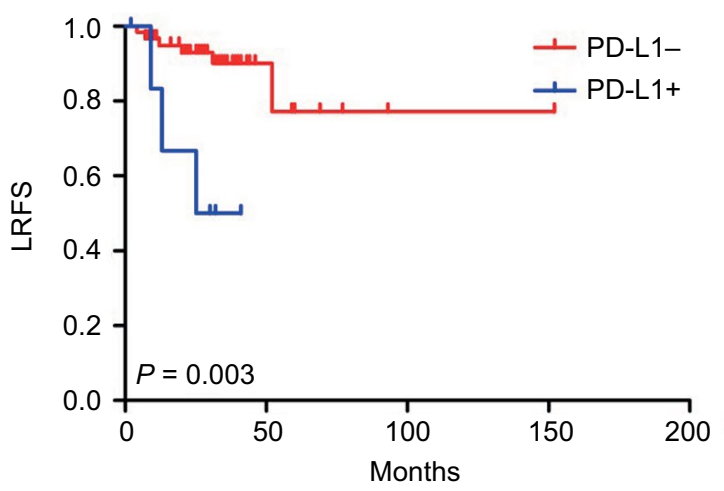

C

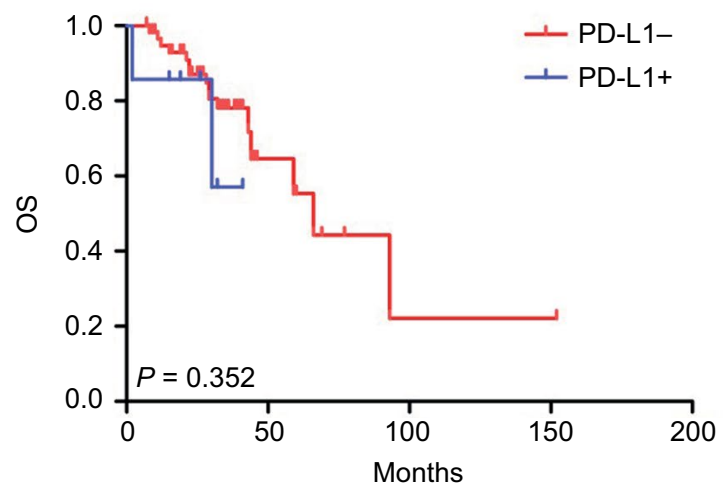

Figure 3 Kaplan-Meier analysis of the DFS, OS, and LRFS.

Note: Positive expression of PD-LI in TCs was significantly associated with LRFS (B), and no significant difference was found between PD-LI expression and DFS or OS (A and $\mathbf{C}$ ).

Abbreviations: DFS, disease-free survival; OS, overall survival; PD-LI, programmed death-ligand I; LRFS, local recurrence-free survival; programmed death-ligand I; $\mathrm{TC}$, tumor cell.

cancer was affected by the high density of tumor-infiltrating lymphocytes and lymphoid reactions..$^{25}$ However, no statistical significance was observed in patients' prognosis in our analysis. Further studies should focus on the impact of IC PD-L1 in rectal cancer.

Nevertheless, it should be noted that this study had not enrolled patients without neoadjuvant RT. Since the study was a retrospective analysis of small sample size, prospective data and a larger sample size are essential to confirm the results. Additional studies are imperative to determine the role of RT in the expression of PD-L1. Lastly, the information about the gene expression profile and signaling pathway in the current study was limited, which hindered further analysis.

\section{Conclusion}

We have identified that the TC PD-L1 might negatively relate to long-term prognosis in LARC receiving neoadjuvant RT and play a critical role in tumor recurrence. On the other hand, the different RT regimens could result in varied PD-L1 expression. These results further supplement the immunological study in rectal cancer and may provide a new strategy in the adjuvant treatment of rectal cancer.

\section{Acknowledgments}

This work was supported by the Fujian Province Natural Science Foundation (2016J01437 and 2017J01260), the Fujian Medical Innovation Project (2015-CX-8), the Young-MiddleAged Backbone Training Project of Fujian Provincial Population and Family Planning Commission (2013-ZQN-ZD-8), the Key Clinical Specialty Discipline Construction Program of Fujian, People's Republic of China, and the National Clinical Key Specialty Construction Program.

\section{Disclosure}

The authors report no conflicts of interest in this work.

\section{References}

1. Siegel RL, Miller KD, Jemal A. Cancer statistics, 2016. CA Cancer J Clin. 2016;66(1):7-30.

2. Benson AB 3rd, Venook AP, Bekaii-Saab T, et al. Rectal cancer, Version 2.2015. J Natl Compr Canc Netw. 2015;13(6):719-728. quiz 728. 
3. Meng X, Huang Z, Teng F, Xing L, Yu J. Predictive biomarkers in PD-1/PD-L1 checkpoint blockade immunotherapy. Cancer Treat Rev. 2015;41(10):868-876.

4. Riella LV, Paterson AM, Sharpe AH, Chandraker A. Role of the PD-1 pathway in the immune response. Am J Transplant. 2012;12(10): 2575-2587.

5. Keir ME, Butte MJ, Freeman GJ, Sharpe AH. PD-1 and its ligands in tolerance and immunity. Annu Rev Immunol. 2008;26:677-704

6. Dong H, Strome SE, Salomao DR, et al. Tumor-associated B7-H1 promotes T-cell apoptosis: a potential mechanism of immune evasion. Nat Med. 2002;8(8):793-800.

7. Ikeda $\mathrm{S}$, Okamoto T, Okano S, et al. PD-L1 is upregulated by simultaneous amplification of the PD-L1 and JAK2 genes in non-small cell lung cancer. J Thorac Oncol. 2016;11(1):62-71.

8. Ilie M, Hofman V, Dietel M, Soria JC, Hofman P. Assessment of the PD-L1 status by immunohistochemistry: challenges and perspectives for therapeutic strategies in lung cancer patients. Virchows Arch. 2016;468(5):511-525.

9. Khalil DN, Smith EL, Brentjens RJ, Wolchok JD. The future of cancer treatment: immunomodulation, CARs and combination immunotherapy. Nat Rev Clin Oncol. 2016;13(5):273-290.

10. Barker HE, Paget JT, Khan AA, Harrington KJ. The tumour microenvironment after radiotherapy: mechanisms of resistance and recurrence. Nat Rev Cancer. 2015;15(7):409-425.

11. Heriot AG, Kumar D. Adjuvant therapy for resectable rectal and colonic cancer. Br J Surg. 1998;85(3):300-309.

12. Deng L, Liang H, Burnette B, et al. Irradiation and anti-PD-L1 treatment synergistically promote antitumor immunity in mice. JClin Invest. 2014;124(2):687-695.

13. Ohigashi Y, Sho M, Yamada Y, et al. Clinical significance of programmed death-1 ligand-1 and programmed death-1 ligand-2 expression in human esophageal cancer. Clin Cancer Res. 2005;11(8):2947-2953.

14. Tamura T, Ohira M, Tanaka H, et al. Programmed death-1 ligand-1 (PDL1) expression is associated with the prognosis of patients with stage II/III gastric cancer. Anticancer Res. 2015;35(10):5369-5376.
15. Shimoji M, Shimizu S, Sato K, et al. Clinical and pathologic features of lung cancer expressing programmed cell death ligand 1 (PD-L1). Lung Cancer. 2016;98:69-75.

16. Hamanishi J, Mandai M, Iwasaki M, et al. Programmed cell death 1 ligand 1 and tumor-infiltrating CD8+ T lymphocytes are prognostic factors of human ovarian cancer. Proc Natl Acad Sci USA. 2007;104(9):3360-3365.

17. Droeser RA, Hirt C, Viehl CT, et al. Clinical impact of programmed cell death ligand 1 expression in colorectal cancer. Eur J Cancer. 2013;49(9): 2233-2242.

18. Lee LH, Cavalcanti MS, Segal NH, et al. Patterns and prognostic relevance of PD-1 and PD-L1 expression in colorectal carcinoma. Mod Pathol. 2016;29(11):1433-1442.

19. Saigusa S, Toiyama Y, Tanaka K, et al. Implication of programmed cell death ligand 1 expression in tumor recurrence and prognosis in rectal cancer with neoadjuvant chemoradiotherapy. Int J Clin Oncol. 2016;21(5):946-952.

20. Rehman JA, Han G, Carvajal-Hausdorf DE, et al. Quantitative and pathologist-read comparison of the heterogeneity of programmed death-ligand 1 (PD-L1) expression in non-small cell lung cancer. Mod Pathol. 2017;30(3):340-349.

21. Chen J, Jiang CC, Jin L, Zhang XD. Regulation of PD-L1: a novel role of pro-survival signalling in cancer. Ann Oncol. 2016;27(3):409-416.

22. Shahabi V, Postow MA, Tuck D, Wolchok JD. Immune-priming of the tumor microenvironment by radiotherapy: rationale for combination with immunotherapy to improve anticancer efficacy. Am J Clin Oncol. 2015;38(1):90-97.

23. Hecht M, Buttner-Herold M, Erlenbach-Wunsch K, et al. PD-L1 is upregulated by radiochemotherapy in rectal adenocarcinoma patients and associated with a favourable prognosis. Eur $J$ Cancer. 2016;65:52-60.

24. Kim JH, Park HE, Cho NY, Lee HS, Kang GH. Characterisation of PD-L1-positive subsets of microsatellite-unstable colorectal cancers. Br J Cancer. 2016;115(4):490-496.

25. Mei Z, Liu Y, Liu C, et al. Tumour-infiltrating inflammation and prognosis in colorectal cancer: systematic review and meta-analysis. $\mathrm{Br} \mathrm{J}$ Cancer. 2014;110(6):1595-1605.
Cancer Management and Research

\section{Publish your work in this journal}

Cancer Management and Research is an international, peer-reviewed open access journal focusing on cancer research and the optimal use of preventative and integrated treatment interventions to achieve improved outcomes, enhanced survival and quality of life for the cancer patient. The manuscript management system is completely online and includes

\section{Dovepress}

a very quick and fair peer-review system, which is all easy to use. Visit $\mathrm{http}: / / \mathrm{www}$.dovepress.com/testimonials.php to read real quotes from published authors. 